\begin{tabular}{|c|c|}
\hline Title & Ice Formation Processes in PEM Fuel Cell Catalyst Lay ers during Cold Startup A nalyzed by Cryo-SEM \\
\hline Author(s) & Tabe, Y utaka; Y amada, Kazuki; Ichikawa, Ryosuke; A oy ama, Y usuke; Suzuki, Kengo; Chikahisa, Takemi \\
\hline Citation & $\begin{array}{l}\text { Journal of the electrochemical society, 163(10), F1139-F1145 } \\
\text { https://doi.org/10.1149/2.1321609jes }\end{array}$ \\
\hline Issue Date & 2016-08-02 \\
\hline Doc URL & http:/hdl.handle.net/2115/64364 \\
\hline Rights & $\begin{array}{l}\text { () The Electrochemical Society, Inc. 2016. All rights reserved. Except as provided under U.S. copyright law, this work } \\
\text { may not be reproduced, resold, distributed, or modified without the express permission of The Electrochemical Society } \\
\text { (ECS). The archival version of this work was published in Journal of the electrochemical society. } 2016 \text { volume 163, } \\
\text { issue 10, F1139-F1145. }\end{array}$ \\
\hline Rights(URL) & http://creativecommons.org/icenses/by/4.0/ \\
\hline Type & article \\
\hline File Information & J. Electrochem. Soc.-2016-Tabe-F1139-45.pdf \\
\hline
\end{tabular}

Instructions for use 


\title{
Ice Formation Processes in PEM Fuel Cell Catalyst Layers during Cold Startup Analyzed by Cryo-SEM
}

\author{
Yutaka Tabe, ${ }^{*, z}$ Kazuki Yamada, Ryosuke Ichikawa, Yusuke Aoyama, Kengo Suzuki, \\ and Takemi Chikahisa*
}

Division of Energy and Environmental Systems, Graduate School of Engineering, Hokkaido University, Sapporo, Hokkaido 060-8628, Japan

\begin{abstract}
For further improvements in the startup ability below freezing and the durability of polymer electrolyte fuel cells, understanding the ice formation mechanism during cold startup is particularly significant. This study observes cross-sectional ice distributions in a catalyst layer (CL) during isothermal galvanostatic operation at $-20^{\circ} \mathrm{C}$ using a cryo-scanning electron microscope. The effects of current density, cathode gas conditions, initial water content of the membrane, and cell temperature on the cold start characteristics and the ice formation process in the CL are evaluated. The observational results show that at higher current densities, the region with active ice formation moves from the membrane to the gas diffusion layer sides during the freezing period and vacant pores remain near the membrane even after cell shutdown, while the pores are completely filled with nearly-uniformly growing ice at lower current density operation. This is consistent with the experimental finding from the cold start characteristics that the estimated amount of ice accumulated in the cell until the shutdown decreases as the current density increases. Contrary to expectations, these changes are largely independent of cathode gas conditions, even with pure oxygen. Additional factors controlling the ice formation process are discussed based on the experimental results.

(c) The Author(s) 2016. Published by ECS. This is an open access article distributed under the terms of the Creative Commons Attribution 4.0 License (CC BY, http://creativecommons.org/licenses/by/4.0/), which permits unrestricted reuse of the work in any medium, provided the original work is properly cited. [DOI: 10.1149/2.1321609jes] All rights reserved.
\end{abstract}

Manuscript submitted June 9, 2016; revised manuscript received July 14, 2016. Published August 2, 2016. This was Paper 1321 presented at the San Francisco, California, Meeting of the Society, October 27-November 1, 2013.

The polymer electrolyte fuel cell (PEFC) is a potential candidate for automotive power sources and portable electricity generators because of its characteristics of high efficiency, high power density, low operating temperature, and other advantageous characteristics. In cold climates, however, ensuring startup and durability of PEFCs at subfreezing conditions is a critical issue for the practical use of PEFC. It has been reported that freezing of water produced by the cathode reaction induces shutdown (voltage failure) during startup at subfreezing temperatures, and this freezing causes various kinds of degradation of the cell performance. ${ }^{1-3}$ Therefore, a number of practicable strategies based on thermal management and control of the residual water present in the cell before cooling and starting have been developed. However, a basic understanding of details of the ice formation process at cold startup, which is particularly-significant for further improvements in the cold startup ability and durability, remains insufficiently addressed in the literature.

Some modeling studies have been conducted to describe the heat and mass transfer, and ice formation during cold startup. ${ }^{4-7}$ The research group of the authors has investigated the performance of a PEFC at temperatures below the freezing point by both simulation and experiments. ${ }^{4}$ That study identified the initial temperature at which self-starting becomes possible, and this is determined by the balance of the produced heat and water generated due to the reaction. With regard to freezing at temperatures closer to zero, like $-10^{\circ} \mathrm{C}$, it was reported that the produced water is present in a supercooled state, and that the freezing behavior in a PEFC can be visualized by infrared thermography. ${ }^{8}$ The freezing was captured as a 2-dimensional propagation in the higher temperature region $\left(\leq 0^{\circ} \mathrm{C}\right)$ caused by the release of heat due to the freezing. Ice or frost formation on the catalyst layer (CL) surface above $-3^{\circ} \mathrm{C}$ was observed directly thorough a silver mesh used as the cathode gas diffusion layer (GDL). ${ }^{9}$ To investigate the ice formation process in more detail, the in-plane distribution of the ice formation in the cells at $-10^{\circ} \mathrm{C}$ was visualized by neutron radiography, ${ }^{10}$ and the water/ice produced in a GDL between -10 and $-20^{\circ} \mathrm{C}$ was imaged by X-Ray tomography. ${ }^{11}$ The freezing mechanism during cold startup was classified into two types based on the results of direct observations of disassembled cell components maintained below freezing: freezing in the cathode $\mathrm{CL}$ at very low

*Electrochemical Society Member.

żE-mail: tabe@eng.hokudai.ac.jp temperatures like $-20^{\circ} \mathrm{C}$, and freezing due to supercooled water at the interface between the $\mathrm{CL}$ and the GDL near $0^{\circ} \mathrm{C}$ like at $-10^{\circ} \mathrm{C} .^{3}$ Tajiri et al. proposed a thorough gas purge process before cold start operation, and estimated the ice distribution in the cathode CL at the end of an isothermal startup at $-30^{\circ} \mathrm{C}$ from the measured startup characteristics. ${ }^{12}$ They suggested that complete filling of the CL with ice would occur at low current densities, while produced water may concentrate in the front portion of the CL and GDL interface at high current densities. An ice sheet formed there may block the oxygen transport into the CL before all pores are occupied by produced water at high current densities. To identify the ice formation process in the CL at very low temperatures, the research on visualization of ice in the CL under the frozen state with nanometer scale resolution is necessary. However, such reports are few. Cryo-scanning electron microscope (cryo-SEM) observations have been conducted to elucidate details of the ice distribution in the $\mathrm{CL}$ at $-20^{\circ} \mathrm{C}$ or $-25^{\circ} \mathrm{C}$; such observations have been carried out with the examined components kept at very low temperatures and in vacuum conditions to avoid thawing and covering by frost deposits. ${ }^{13-16}$ Thompson et al. reported that cryo-SEM images after $-20^{\circ} \mathrm{C}$ startups indicated that filling the $\mathrm{CL}$ with ice occurs from the membrane moving outwards toward the GDL, and at lower current densities there is a more even filling of the CL across the thickness of the CL. ${ }^{13,14}$ Thompson et al. used pure oxygen as the cathode gas in the experiments. Li et al. also conducted a cryo-SEM investigation and reported that the catalyst surface was completely covered after the shutdown of constant voltage operation at $-25^{\circ} \mathrm{C}$ with air. ${ }^{15}$ At the midpoint of the operation they observed two distinct regions, a dense layer filled with ice close to the GDL and a porous layer containing less ice which was close to the membrane in the CL. Taken together, these observations appear to suggest different behaviors during the ice formation process in the CL, and further research is necessary to fully resolve and elucidate details of the effects of the current density and the cathode gas conditions on the freezing process. Here, it should be noted that the operating conditions must be carefully controlled by gas purging before the cold startup, because the characteristics of the operation are strongly affected by the initial residual water present inside the cell before the startup is attempted. ${ }^{17}$

This study observed the cross-sectional ice distribution in a CL of a PEFC during isothermal galvanostatic operation at $-20^{\circ} \mathrm{C}$ using a cryo-SEM. The effects of the startup current density, cathode gas conditions, initial water content of the membrane, and cell temperature on the cold start characteristics and the ice distribution in the CL were 
Table I. Experimental conditions of the cold start operation investigated here.

\begin{tabular}{|c|c|c|c|c|c|c|c|}
\hline \multirow[b]{2}{*}{ No. } & \multirow{2}{*}{$\begin{array}{l}\text { Startup } \\
\text { temp. } /{ }^{\circ} \mathrm{C}\end{array}$} & \multirow{2}{*}{$\begin{array}{l}\text { Current density } \\
/ \mathrm{A} \mathrm{cm}^{-2}\end{array}$} & \multirow{2}{*}{$\begin{array}{l}\mathrm{RH} \text { of wet } \\
\text { purge } \mathrm{N}_{2} / \%\end{array}$} & \multirow{2}{*}{$\begin{array}{l}\text { Ramp up } \\
\text { period/s }\end{array}$} & \multirow[b]{2}{*}{ Cathode gas } & \multicolumn{2}{|c|}{ Stoichio. ratio } \\
\hline & & & & & & Cathode & $\overline{\text { Anode }}$ \\
\hline 1 & -20 & 0.01 & 24 & 80 & Air & 22 & 22 \\
\hline 2 & & 0.04 & & & & 20 & 20 \\
\hline 3 & & 0.08 & & & & 20 & 20 \\
\hline 4 & -20 & 0.01 & 100 & 0 & Air & 22 & 22 \\
\hline 5 & & 0.04 & & & & 20 & 20 \\
\hline 6 & & 0.08 & & & & 20 & 20 \\
\hline 7 & -20 & 0.08 & 68 & 60 & Air & 22 & 22 \\
\hline 8 & & & & & $10 \% \mathrm{O}_{2}, 2 \mathrm{~atm}$ & 22 & 10 \\
\hline 9 & & & & & Air, 2atm & 22 & 22 \\
\hline 10 & -20 & 0.01 & 24 & 80 & $\mathrm{O}_{2}$ & 20 & 20 \\
\hline 11 & & 0.04 & & & & 20 & 20 \\
\hline 12 & & 0.08 & & & & 20 & 20 \\
\hline 13 & -20 & 0.01 & 24 & 80 & Air & 20 & 19 \\
\hline 14 & & 0.04 & & & & 20 & 20 \\
\hline 15 & & 0.08 & & & & 20 & 20 \\
\hline 16 & -20 & 0.08 & 68 & 60 & Air, 2atm & 22 & 22 \\
\hline 17 & -20 & 0.20 & 68 & 40 & $\mathrm{O}_{2}$ & 20 & 20 \\
\hline 18 & -20 & 0.20 & 100 & 0 & Air & 20 & 20 \\
\hline 19 & -30 & 0.20 & 100 & 0 & Air & 20 & 20 \\
\hline
\end{tabular}

investigated; and the ice formation processes depending on the startup conditions were identified. Further, the factors controlling the ice formation processes are discussed based on the experimental results.

\section{Experimental Apparatus and Methods}

A single cell with an active area of $25 \mathrm{~cm}^{2}(5 \mathrm{~cm} \times 5 \mathrm{~cm})$ was used in this study. The details of the specifications are in Ref. 3. The heat capacity per reaction area of the cell is much larger than that of an ordinary PEFC stack, so the cell temperature, controlled by the ambient temperature, can be maintained fairly constant (isothermal) during the cold start operation in low output conditions. A membrane electrode assembly (MEA) with a $30 \mu \mathrm{m}$ thick polymer electrolyte membrane, two $10 \mu \mathrm{m}$ thick CLs (GORE-TEX, PRIMEA 5570), and two $0.2 \mathrm{~mm}$ thick carbon papers with a micro porous layer (MPL) on the CL side (GORE-TEX, CARBEL) was used in this study. The MPL is hydrophobic and its thickness as estimated from SEM images is about $30 \mu \mathrm{m}$. The details of the apparatus for evaluating the fuel cell performance are also provided in Ref. 3. In the purging process, basic gas supply lines were used to ensure accurate control of the initial residual water conditions in the cell, and purpose-installed dry lines which are independent of the basic gas supply lines were used to eliminate uncertainties that could arise from residual moisture in the gas lines in the cold start operation below freezing. The cell was set vertically in a thermostatic chamber (HITACHI, EC-25MTP) with a controllable temperature range of -40 to $100^{\circ} \mathrm{C}$, and the temperatures of the cell and the supplied gas were controlled by the chamber temperature. The thermostatic chamber has a window and two handling holes at the front, which make it possible to disassemble the cell and place the sample removed from the cell into liquid nitrogen in the chamber maintaining subfreezing temperatures. The high-frequency resistance was measured as the cell resistance by an alternating impedance meter at $1 \mathrm{kHz}$ (TSURUGA, MODEL 3566). For the observation of the cross-section of the CL under the frozen state with nanometer scale resolution, a SEM (JEOL, JSM-6701F) equipped with a cold stage, and a cryo-preparation and transfer system (GATAN, ALTO 2500) was used.

The experiments were divided into two processes, the cold startup in the thermostatic chamber and the observations in a cryo-SEM unit. The initial conditions of the water in the cell before the startup operation were carefully controlled by a procedure which was similar to the method proposed by Tajiri et al. ${ }^{12}$ which will be described next. Following a preconditioning process to enhance the performance of the MEA, dry nitrogen was supplied to remove the liquid water in the cell until the measured cell resistance increased to a specific value, here $8.8 \Omega \mathrm{cm}^{2}$. Then, humidified nitrogen was supplied without powergenerating operation to control the initial state of the residual water in the cell. This wet purge was continued to achieve an equilibrium state of the MEA, until a steady level of cell resistance was established, this typically lasted for 3 to 5 hours. The cell resistance at the equilibrium state depended on the wet purge condition, and three humidification conditions of the nitrogen were used: a cell temperature of $60^{\circ} \mathrm{C}$ and bubbler temperatures of $32^{\circ} \mathrm{C}$ (relative humidity of nitrogen $24 \%$ ), $52^{\circ} \mathrm{C}(\mathrm{RH} 68 \%)$, or $60^{\circ} \mathrm{C}(\mathrm{RH} 100 \%)$. The steady values were around $0.74,0.15$, and $0.08 \Omega \mathrm{cm}^{2}$, respectively. After the wet purge, the cell and the chamber were cooled to $-20^{\circ} \mathrm{C}$ without ice formation, and cell operation was started and maintained at a constant current density after an initial current ramp up period. The ramp up period was determined to ensure stable startup and clear evaluation of the cell operation. The anode and the cathode gases were dry hydrogen, and dry air or pure oxygen, respectively. The flow rates were set to sufficiently-high stoichiometric ratios around 20 for a relatively low current density of around $0.08 \mathrm{~A} \mathrm{~cm}^{-2}$ to avoid the effect of changes in oxygen concentration along the channels. The outlet pressure of the gases was 1atm. Details of the experimental conditions are summarized in Table I, with special conditions such as 2atm outlet pressure of the cathode gas and $-30^{\circ} \mathrm{C}$ startup temperature included. Superior repeatability was confirmed under various conditions at very low temperatures like $-20^{\circ} \mathrm{C}$, as also reported in Refs. 3 and 18, and this is considered to be due to the careful control of the initial residual water in the cell. The cell voltage, the cell resistance, and the temperatures of both cell and supplied gas were recorded digitally.

For the cryo-SEM observations, a sample of the MEA as removed from the cell was immediately immersed in liquefied nitrogen in the thermostatic chamber. The undamaged sample was cut into smaller pieces and an approximately $8 \mathrm{~mm} \times 8 \mathrm{~mm}$ piece of the sample was set on a sample holder in the liquefied nitrogen. Then, the sample was moved to a preparation chamber at $-100^{\circ} \mathrm{C}$ in the cryo-SEM, and the chamber was evacuated. Finally, the sample was cut by a cold knife in the chamber, where the vacuum condition prevented the cut section area of the sample from becoming covered with frost. The cut section area was coated with gold-palladium alloy (Au-Pd) for clearer observations, and then transferred at $-150^{\circ} \mathrm{C}$ to the SEM stage equipped with a cryo-unit. The electron beam was used with an acceleration voltage of $5 \mathrm{kV}$.

Figure 1 shows examples of cryo-SEM images of cross-sections of the cathode $\mathrm{CL}$ (a) after the wet purge at $60^{\circ} \mathrm{C}$ and cooling to $-20^{\circ} \mathrm{C}$, and (b) after the shutdown of a $0.04 \mathrm{~A} \mathrm{~cm}^{-2}$ startup at $-20^{\circ} \mathrm{C}$. Here, 
(a) After wet purge and cooling

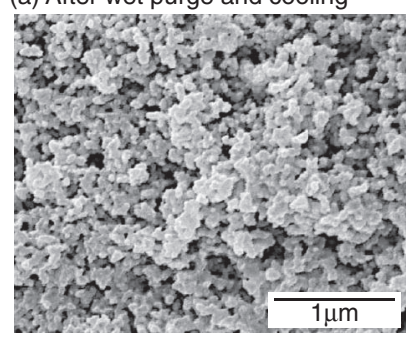

(b) After shutdown

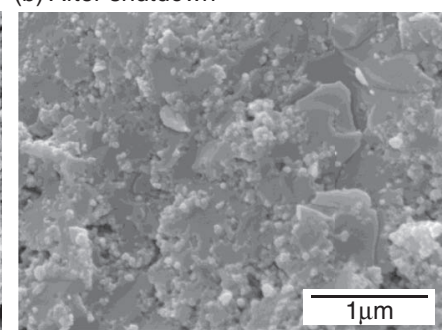

Figure 1. Cryo-SEM images of cross-sections of the cathode CL, (a) after the wet purge by nitrogen with $24 \% \mathrm{RH}$ at $60^{\circ} \mathrm{C}$ and cooling to $-20^{\circ} \mathrm{C}$, and (b) after the shutdown of the $0.04 \mathrm{~A} \mathrm{~cm}^{-2}$ startup at $-20^{\circ} \mathrm{C}$.

nitrogen with $24 \% \mathrm{RH}$ was used for the wet purge. After the wet purging and cooling to $-20^{\circ} \mathrm{C}$ without power-generating operation, the nanometer scale porous structure of the CL can be clearly observed in Fig. 1a, showing an absence of ice before operation at $-20^{\circ} \mathrm{C}$. This is different from the result reported by Li et al. ${ }^{15}$ They reported that more than $70 \%$ of pores of the CL are filled with ice after the purge process without any subzero operation, and also pointed out that insufficient purge and water migration during the cooling process could be the reasons for the presence of this ice in their results. The result in Fig. 1a indicates that the purge process in this study was effective to completely remove the initial residual water in the CL and that there is no migration of water in the MEA during the cooling process after the purging. After the shutdown here, there are no pores in the CL in Fig. 1b, and this suggests that the pores are completely filled with ice produced by the $0.04 \mathrm{~A} \mathrm{~cm}^{-2}$ operation. This allows the conclusion that the cryo-SEM investigation can clearly identify the ice distribution in the CL, although the quantitative analyses of the ice amount and the CL structure are difficult.

\section{Results and Discussion}

Basic cold start characteristics and the effect of startup current density.-The cold start characteristics, the changes in the cell voltage and resistance, for various current densities at $-20^{\circ} \mathrm{C}$ using air as the cathode gas are shown in Fig. 2. In addition to the operation until the cell shuts down where the cell voltage drops away completely, the results where the operation was stopped before the shutdown are also shown for the cryo-SEM investigation of the ice formation process below: in each of the figures, two or three sets of the data were plotted for the experiments with different timings when the operation was stopped, early in the freezing, halfway through the freezing, and until shutdown. Humidified nitrogen with $24 \% \mathrm{RH}$ was used in the wet purge at $60^{\circ} \mathrm{C}$, and the applied current densities were initially increased for $80 \mathrm{~s}$ followed by constant values: (a) 0.01 , (b) 0.04 , and (c) $0.08 \mathrm{~A} \mathrm{~cm}^{-2}$, experiment numbers 1 to 3 in Table I. After the initial current ramping up period, typical characteristics for the isothermal galvanostatic operation at a low temperature like $-20^{\circ} \mathrm{C}$, as reported in Refs. 3 and 12, are confirmed at all of the current densities. The cell resistance decreases with a gradual increase in the cell voltage and then approaches a steady value. This is because the water produced by the cathode reaction humidifies the polymer electrolyte membrane due to back diffusion; the membrane resistance comprising a large part of the cell resistance becomes smaller with wetter states. ${ }^{19}$ Then, the cell voltage rapidly falls off and operation stops, and this shutdown of operation can be considered to be caused by the freezing of the water produced in the cell, where the formed ice induces an interruption in the supply of reaction gas.

The effects of the startup current density on the cold start characteristics were evaluated by the amount of produced water, which was calculated by multiplying the rate of water produced by the cathode reaction, $\dot{m}_{w}^{\text {react }}$, and the duration of the operation, $\Delta t$ : $\dot{m}_{w}^{\text {react }} \Delta t=i / 2 F \times M_{\mathrm{H}_{2} \mathrm{O}} \times \Delta t$, where $i$ is the current density, $F$ Faraday's constant, and $M_{H 2 O}$ the molecular weight of water. The
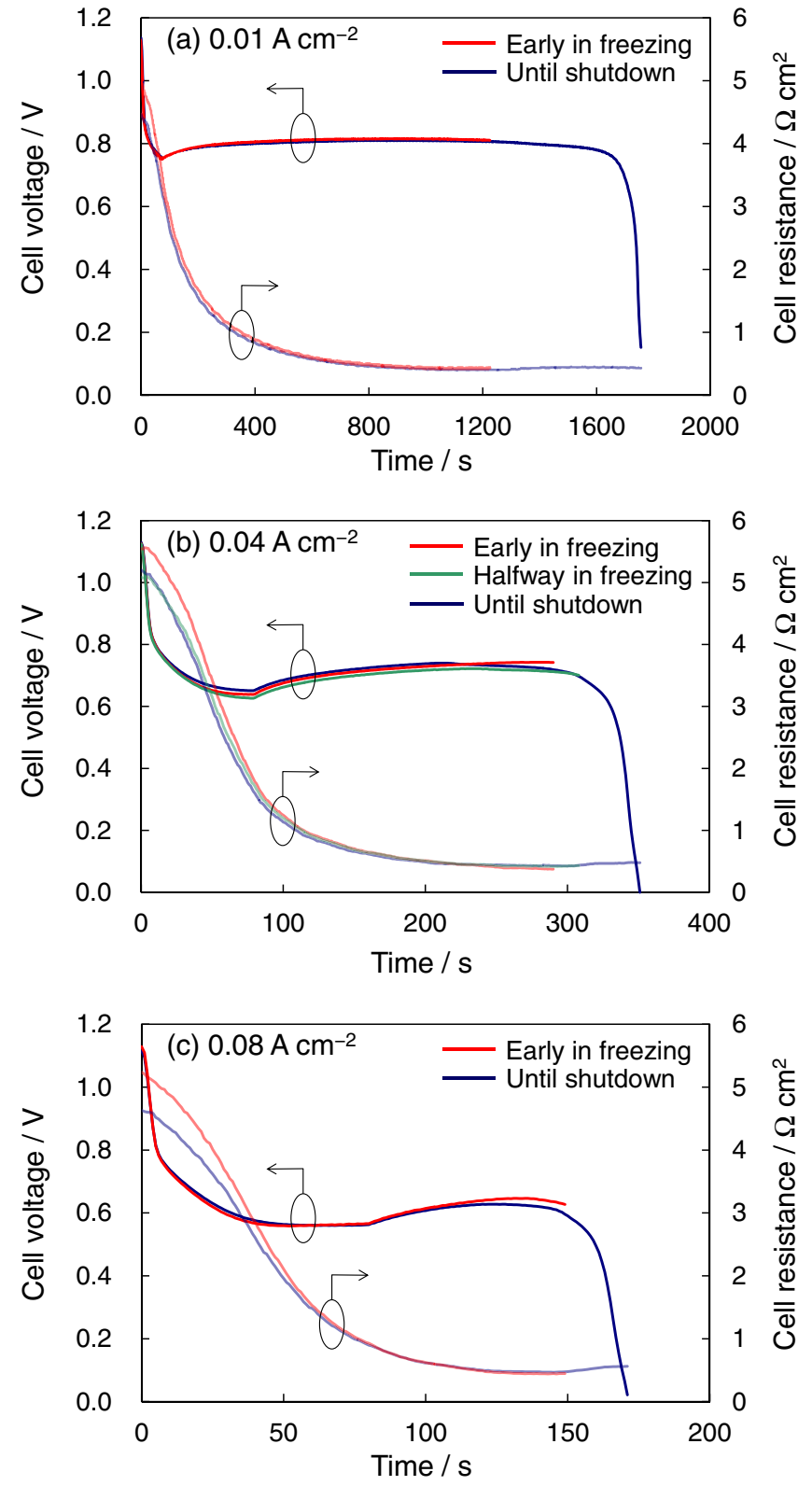

Figure 2. Cell voltages and resistances at three current densities for different operating durations at $-20^{\circ} \mathrm{C}$, (a) $0.01 \mathrm{~A} \mathrm{~cm}^{-2}$ for early in the freezing and until the shutdown, (b) $0.04 \mathrm{~A} \mathrm{~cm}^{-2}$ for early in and halfway through the freezing, until the shutdown, and (c) $0.08 \mathrm{~A} \mathrm{~cm}^{-2}$ for early in the freezing and until the shutdown, (No. 1 to 3 in Table I).

calculated amounts of water produced during the whole duration of the operation were divided into three parts to be able to discuss the location of the water accumulation in the cell, as shown in Fig. 3. The results for the experiments using the wet purge with $100 \% \mathrm{RH}$ nitrogen at $60^{\circ} \mathrm{C}$ (experiments 4 to 6 in Table I) are also shown in Fig. 3; in these cases, the ramp up period was set to zero as the freezing started earlier due to the higher initial water content. The amount of water removed by the reactant gases was calculated with the assumption that a part of the water produced during the startup is removed by the saturated cathode gas exiting the cell., ${ }^{3,9}$ The rate of water removal by the gas is $\dot{m}_{w}^{\text {removed }}=\left(N_{c} / A-i / 4 F\right) \times p_{w}^{\text {sat }} /\left(p_{c}-p_{w}^{\text {sat }}\right) \times M_{H_{2} O}$, where $N_{c}$ is the molar flow rate of the cathode gas, $A$ the active area, and $p_{w}{ }^{\text {sat }}$ and $p_{c}$ the pressures of the saturated vapor and cathode gas. The amount of water remaining in the cell (residual water in the following) was estimated as the produced water minus the water removed by the 


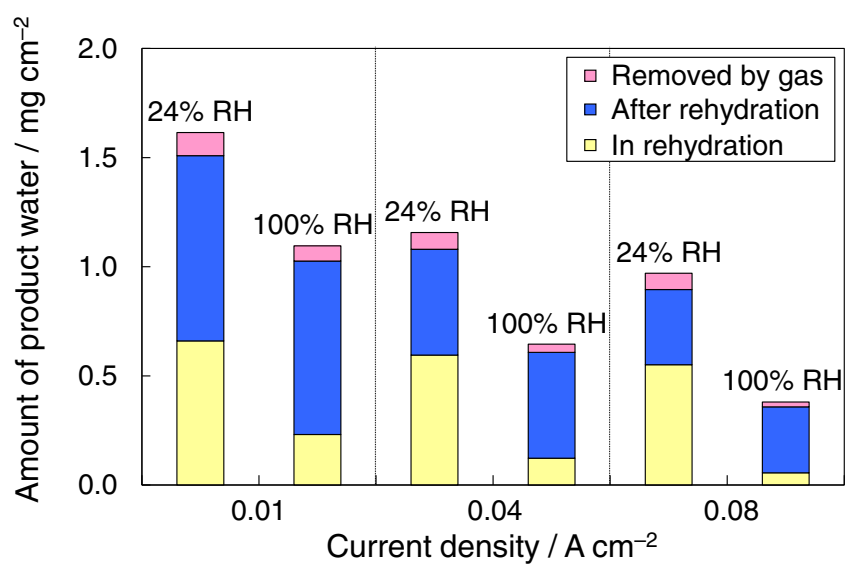

Figure 3. Amounts of water produced throughout the operation, divided into three: the estimated residual water produced during the membrane rehydration, after the end of the rehydration till the shutdown, and the estimated water removed by the reactant gases at $-20^{\circ} \mathrm{C}$, (No. 1 to 6 in Table I).

reactant gases, and converted into two: the amount of residual water produced during the membrane rehydration (this could also be termed "water uptake by the membrane") period, and that after the membrane is fully rehydrated and till shutdown. In this study, the period of the membrane rehydration was defined as the period when the cell voltage was increasing, corresponding to the period when the cell resistance was decreasing and clearly indicates the end of the membrane rehydration. In Fig. 3 the amount of water produced during the total operation equals the sum of the amounts of residual water in and after the membrane rehydration, and the water removed by the gas. The results show that the higher startup-current densities decrease the amount of water produced during the whole of the period of operation, as also reported previously., 32,13 The amounts of residual water during the membrane rehydration period decreases slightly as the current density increases in both the cases with the $24 \%$ and $100 \%$ RH wet purges, but the effect of the initial water content determined by the wet purge condition is more noticeable: the amounts of the residual water in the membrane rehydration with the $100 \% \mathrm{RH}$ purge are much smaller than those with the $24 \% \mathrm{RH}$ purge. This is because the water storage capacity in the MEA depends on the initial water content. ${ }^{3,12,13}$ The reason for the smaller water amount during the membrane rehydration period with the higher current density may be that the freezing at $-20^{\circ} \mathrm{C}$ occurs before the produced water uptake by the membrane is complete, ${ }^{3}$ and the start of freezing becomes earlier as the current density is higher. The tiny amounts of the residual water in the membrane rehydration period with the $100 \%$ RH wet purge are due to the difficulty of achieving and maintaining the saturated state of the MEA during and after the purge process. Then, the residual water produced after the end of the membrane water uptake can be considered to be released and to represent the part of water that freezes mainly in the pores of the cathode CL, and this is the ice that disrupts the cell operation. The period from the end of the membrane rehydration till the shutdown is termed the freezing period in the following. The amount of residual water produced during the freezing period (after the rehydration period in Fig. 3), which corresponds to the accumulated amount of ice present in the CL pores, decreases significantly with increasing startup current density, and results in the smaller amount of water produced during the total operation with higher current density. This is consistent with the results reported by Tajiri et al. ${ }^{12}$ and Thompson et al. ${ }^{13}$ that the water storage capacity of the cathode CL decreases with increasing current density. Additionally, the amounts of residual water produced during the freezing period are little affected by the wet purge condition even with the $100 \%$ RH nitrogen, as suggested by Fig. 3. This indicates that the process during the membrane rehydration has little effect on the processes taking place during the freezing period, and allows distinguishing the discussion into two periods. (a) $0.04 \mathrm{~A} \mathrm{~cm}^{-2}$
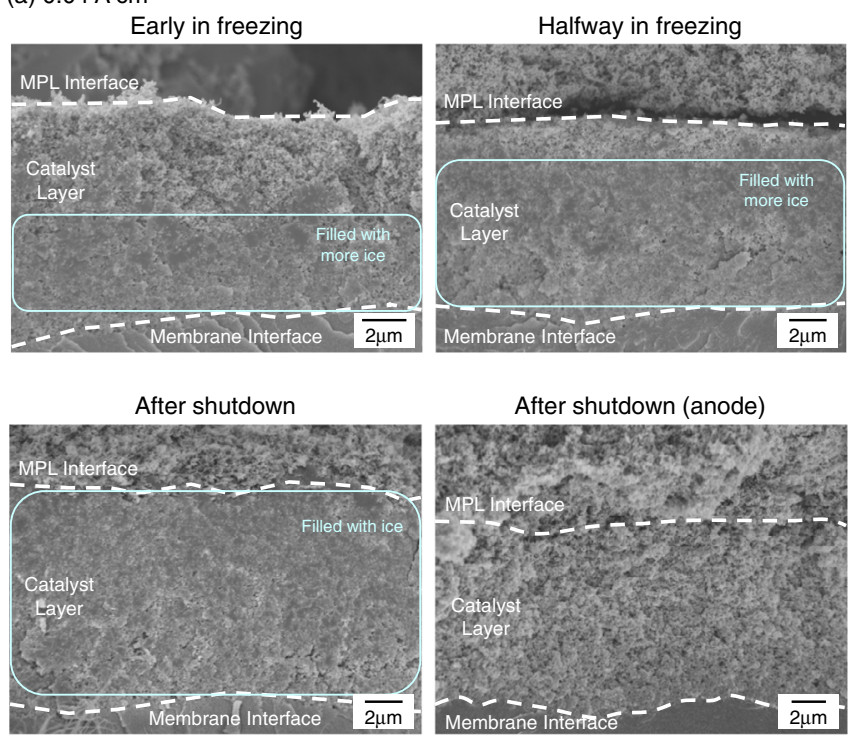

(b) $0.01 \mathrm{~A} \mathrm{~cm}^{-2}$
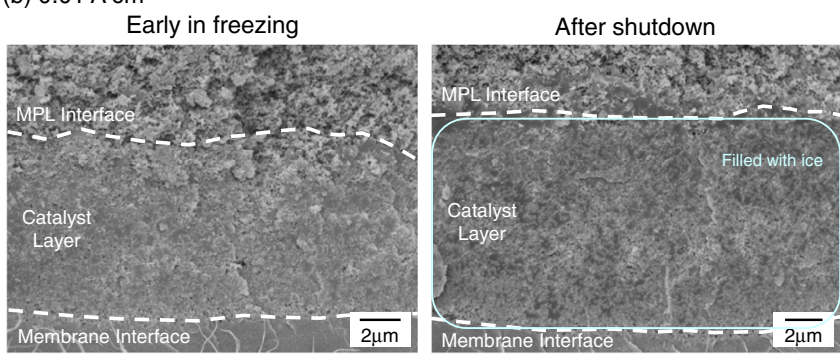

(c) $0.08 \mathrm{~A} \mathrm{~cm}^{-2}$
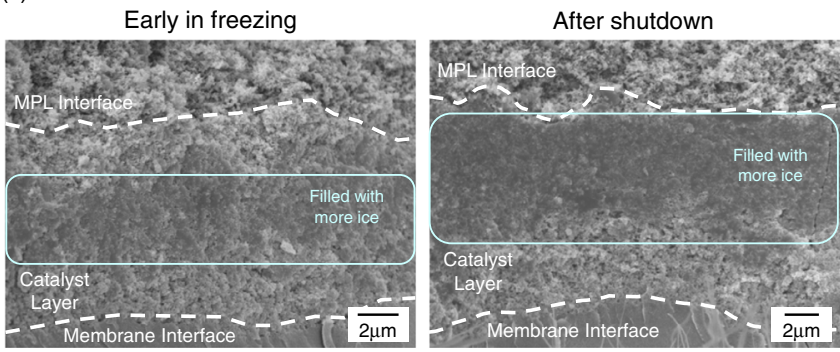

Figure 4. Cryo-SEM images of cross-sections of the CL after the operation in Fig. 2, (a) $0.04 \mathrm{~A} \mathrm{~cm}^{-2}$ for early and halfway in the freezing at the cathode side, after the shutdown at the cathode and anode sides (No. 2 in Table I), and (b) $0.01 \mathrm{~A} \mathrm{~cm}^{-2}$ and (c) $0.08 \mathrm{~A} \mathrm{~cm}^{-2}$ for early in the freezing and after the shutdown at the cathode side, (No. 1 and 3 ).

Ice formation processes at different current densities.-To investigate the ice formation process, cross-sections of the CL were observed by the cryo-SEM after the experiments in Fig. 2. Figure $4 \mathrm{a}$ shows images from the $0.04 \mathrm{~A} \mathrm{~cm}^{-2}$ operation at three different timings during the freezing: images of the cathode CL early (top left panel) and halfway through the freezing period (top right panel), and images of the cathode (bottom left panel) and anode CLs (bottom right panel) after the shutdown of operation. Early in the freezing period, there is a region with much ice near the membrane interface in the cathode CL. There are remaining porous parts with little ice near the micro-porous layer (MPL) interface. As suggested by the images halfway through the freezing period (top right panel) and after the shutdown (bottom left panel), the region with much ice has extended toward the MPL. This indicates that ice formation starts preferentially near the membrane interface and that the region with active ice formation moves to the region near the MPL interface with the filling of the 
CL pores. This progress of the ice formation is in agreement with the observations reported by Thompson et al. using pure oxygen as the cathode gas. ${ }^{14}$ After the shutdown, there is no ice at the anode CL, as in the image after shutdown (at the anode), the bottom right panel of Fig. $4 \mathrm{a}$, and this was the case at all of operating conditions observed in this study at the anode CL. This suggests that the amount of water transported and accumulated in the anode CL is negligible.

Cathode CL images at the startup with a lower current density, $0.01 \mathrm{~A} \mathrm{~cm}^{-2}$, are shown in Fig. $4 \mathrm{~b}$ at two timings, early in the freezing and after the shutdown. The ice distribution is relatively uniform throughout the CL early in the freezing, and after the shutdown all of the area across the pores of the CL is filled with ice. This indicates that the ice formation rate at the cathode CL remains uniform throughout the freezing process. This result is also in agreement with the observations by Thompson et al. ${ }^{13,14}$ These results would suggest that the ice formation process depends on the magnitude of the current density, even when the ice distributions in the images after the shutdown appear to be similar at 0.04 and $0.01 \mathrm{~A} \mathrm{~cm}^{-2}$. The estimated amount of ice in the CL after the shutdown at $0.01 \mathrm{~A} \mathrm{~cm}^{-2}$ is larger than that at $0.04 \mathrm{~A} \mathrm{~cm}^{-2}$ in Fig. 3, suggesting that the saturation of the ice in the $\mathrm{CL}$ is the result of different processes despite the similar appearance of the ice distributions after the shutdown (Figs. $4 \mathrm{a}$ and $4 \mathrm{~b}$ ). The reasons for this will be discussed below.

The different ice formation processes discussed above could be explained by different reaction rate distributions across the cathode CL. The proton conductivity of a polymer electrolyte decreases at lower temperatures,${ }^{19}$ and the higher reaction rate near the membrane interface is estimated to be due to the significant decrease in the proton conductivity of the ionomer in the CL below freezing, even in the range of relatively-low current densities at cold startup. ${ }^{20}$ As protons are supplied from the anode side through the membrane, there is a lower reaction rate in the region far from the membrane interface, and the unevenness of the reaction rate becomes more pronounced with higher current densities. The observed ice formation early in the freezing (in Figs. 4a and 4b) conforms to this explanation, and could suggest that the water produced after the end of the membrane water uptake may be estimated to be available for filling the pores and to freeze at or close to the position where it is produced. The explanation and estimate here are supported by the reported ice-crystallization kinetics in the $\mathrm{CL}^{21}$ that the induction time, which is a period until nucleation and growth of ice occurs, is not long and limited to a couple of seconds at $-20^{\circ} \mathrm{C}$.

Figure $4 \mathrm{c}$ shows cathode CL images in the startup at a higher current density, $0.08 \mathrm{~A} \mathrm{~cm}^{-2}$, at two time points, early in the freezing and after the shutdown. Here, early in the freezing considerable amounts of ice are observed in the middle of the CL, and the region filled with ice grows toward the MPL and GDL sides as operation progresses. Even after the shutdown of operation, there are empty pores in the CL near the membrane interface. This suggests that the region with active ice formation moves from the membrane to the MPL sides during the freezing with vacant pores remaining near the membrane, and that the continuous ice layer formed near the MPL interface acts to block the oxygen transport into the CL, resulting in the shutdown. These results at the higher current density are reasonably consistent with the observations by $\mathrm{Li}$ et al. using air as the cathode gas, ${ }^{15}$ although $\mathrm{Li}$ et al. observed two distinct regions in the CL at the midpoint of the operation before the CL was completely covered with ice at the shutdown: a dense layer filled with ice close to the GDL and a porous layer holding less ice close to the membrane. The movement of a more active ice formation region with vacant pores remaining near the membrane at the higher current density has not been reported in cryo-SEM investigations published so far. ${ }^{13-15}$ This would be a critical process to consider when attempting to determine the ice storage capacity of the CL: the smaller amount of residual water after the membrane rehydration at $0.08 \mathrm{~A} \mathrm{~cm}^{-2}$ in Fig. 3 expresses a smaller amount of ice accumulated in the cathode CL. This can be explained by empty pores remaining near the membrane interface, although a quantitative comparison of the accurate ice amounts is difficult to establish based on the cryo-SEM images here. This amount at
$0.04 \mathrm{~A} \mathrm{~cm}^{-2}$ is also smaller than that at $0.01 \mathrm{~A} \mathrm{~cm}^{-2}$ in Fig. 3, and the lower amount indicates that the pores are not completely filled with ice near the membrane after the shutdown in Fig. 4a. Overall, this would suggest the conclusion that at higher current densities, during the period early in the freezing, the reaction is more active and larger amounts of ice are formed near the membrane interface because of the very low proton conductivity; the region with active ice formation then moves from the membrane to the GDL side during the freezing before the CL pores are not completely filled with ice near the membrane interface. The reasons for the movement of the more active ice formation region to near the MPL interface at higher current densities will be discussed next.

Effect of cathode gas conditions.-We expected that the most likely factor to induce the active reaction near the MPL is the oxygen supply from the MPL and GDL sides, and that the change in oxygen concentration in the $\mathrm{CL}$ pores would dominate the distribution of the ice formation rate late in the freezing period. To investigate the effect of the ability to supply oxygen by the diffusion through the CL pores, two different cathode gas conditions were investigated. The cold start characteristics and the amounts of produced water were compared with those at the normal condition with air at $1 \mathrm{~atm}$. One cathode gas condition is $10 \%$ oxygen and $90 \%$ nitrogen at $2 \mathrm{~atm}$ total pressure. In this condition, the partial pressure of the oxygen is the same as that at the normal air condition, and the molecular diffusion coefficient of oxygen becomes half with the molecular diffusion inversely proportional to the total pressure of the gas; the Knudsen diffusion coefficient is independent of the gas pressure. Therefore, the result with $10 \%$ oxygen at $2 \mathrm{~atm}$ will show the effect of the deterioration in the molecular diffusion. The other cathode gas condition is air at a $2 \mathrm{~atm}$ outlet pressure. The partial pressure of oxygen is now twice, and the molecular diffusion coefficient of oxygen becomes half. This improves the oxygen supply through the CL pores only by the Knudsen diffusion. In the molecular diffusion, the effect of the increase in the oxygen partial pressure is canceled by the decrease in the molecular diffusion coefficient. Thus, the result with air at $2 \mathrm{~atm}$ shows the effect of the improvement in the Knudsen diffusion. The experiments for the comparison here are 7 to 9 in Table I. Figure 5a shows the changes in the cell voltage and resistance at $0.08 \mathrm{~A} \mathrm{~cm}^{-2}$ for the three different cathode gas conditions. The changes in the cell voltage for the three cases are very similar, although the voltage for air at 2 atm is slightly higher due to the higher partial pressure of the supplied oxygen. In all of the cathode gas conditions, the operations shut down around $130 \mathrm{~s}$.

To discuss the effect of the oxygen supply further, pure oxygen operation was also investigated. Figure $5 \mathrm{~b}$ plots the cold start characteristics with pure oxygen and air at $0.04 \mathrm{~A} \mathrm{~cm}^{-2}$ (experiments 11 and 14 in Table I). Except for the higher voltage level of the pure oxygen operation, the cell voltage and resistance changes are also similar; and the shutdown occurs around $400 \mathrm{~s}$ in both cases.

The calculated water amounts for the various cathode gas conditions in Fig. 5 are further detailed in Fig. 6 for experiments 7 to 15 (Table I). In Fig. 6a, the water amounts for the experiments at $0.08 \mathrm{~A} \mathrm{~cm}^{-2}$ with the three different cathode gas conditions in Fig. $5 \mathrm{a}$ are very similar, suggesting that the effect of the oxygen supply on the length of operation is negligible. Further, there is little difference in the water amounts with pure oxygen and air operation at the three different current densities (experiments 10 to 15 , Table I), as shown in Fig. 6b. The total amounts of water produced during the operation and the residual water in the membrane rehydration at $0.08 \mathrm{~A} \mathrm{~cm}^{-2}$ are larger than those at the three different cathode gas conditions in Fig. 6 a because of the lower RH of the wet purge condition. These results also suggest that the durations of operation with the $-20^{\circ} \mathrm{C}$ startup are little affected by the oxygen supply, even when using pure oxygen. Further, these results would suggest that the oxygen supply from the GDL side does not dominate the more active ice formation reaction near the MPL and GDL sides late in the freezing period.

To investigate the effect of the cathode gas condition on the ice formation process, the cross-sectional distributions of the cathode CL after the shutdown were investigated by the cryo-SEM. Figures $7 \mathrm{a}$ and $7 \mathrm{~b}$ 

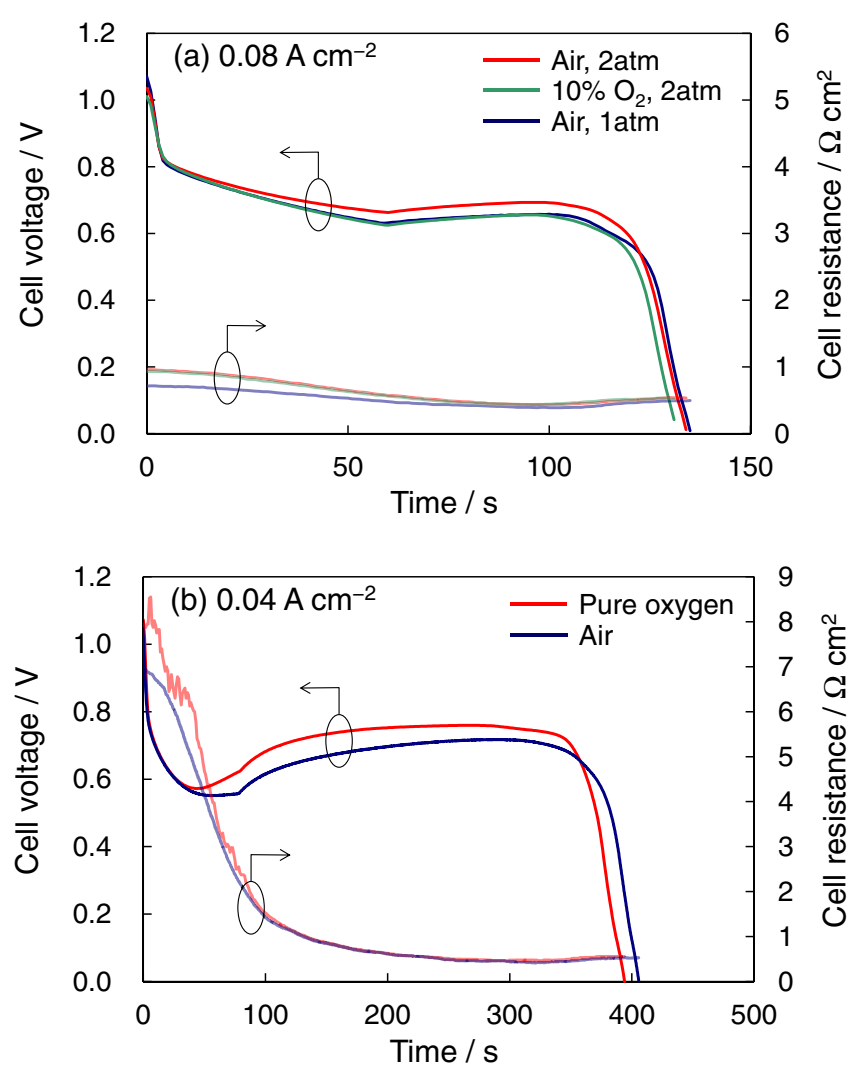

Figure 5. Cell voltages and resistances for different cathode gas conditions, (a) $0.08 \mathrm{~A} \mathrm{~cm}^{-2}$ with air at $1 \mathrm{~atm}, 10 \% \mathrm{O}_{2}$ at $2 \mathrm{~atm}$, and air at $2 \mathrm{~atm}$ (No. 7 to 9 in Table I), and (b) $0.04 \mathrm{~A} \mathrm{~cm}^{-2}$ with pure oxygen and air at 1atm (No. 11 and 14).

show images for (a) $0.08 \mathrm{~A} \mathrm{~cm}^{-2}$ operation with air at 2atm and (b) $0.20 \mathrm{~A} \mathrm{~cm}^{-2}$ with pure oxygen, experiments 16 and 17 in Table I. In both cases, there is much ice filling the CL pores near the MPL interface. The distribution after the $0.08 \mathrm{~A} \mathrm{~cm}^{-2}$ shutdown with air at 2atm (Fig. 7a) is very similar to that with air at $1 \mathrm{~atm}$, as shown in Fig. 4c. In Fig. 7b, after the higher current density $\left(0.20 \mathrm{~A} \mathrm{~cm}^{-2}\right)$ shutdown with pure oxygen, the region filled with much ice appears narrower, and this indicates that active ice formation near the MPL has been more pronounced. These observations support the previous suggestion that the oxygen supply does not dominate the ice distribution, and suggest that the different ice distributions reported by Thompson et al. using pure oxygen ${ }^{14}$ and Li et al. using air ${ }^{15}$ were caused mainly by the magnitude of the current density, not by the cathode gas conditions. Simplified analyses using the agglomerate and the CL models developed by the authors ${ }^{20}$ suggest that a steep reduction in oxygen diffusivity in the CL pores due to ice formation, something which is difficult to estimate by conventional models, is necessary to change the ice formation rate throughout the CL at relatively-low current densities of cold startup. Further, even if a drastic reduction is possible, the similar durations of operation until the shutdown and the similar ice distributions in the CL under the various cathode gas conditions cannot be explained by the oxygen transport.

Factors controlling the ice formation process.-The above experimental results indicated that the oxygen transport is not a major cause of the larger amount of ice formed in the CL near the MPL interface. An alternative reason for the active ice formation near the MPL side could be the effects of the produced water transported to the membrane ${ }^{12}$ and the heat generated by the reaction ${ }^{15}$ as has been pointed out in the literature. However, the experimental results in Figs. 3 and 6 indicate that the residual water produced after the end of the membrane water uptake is released and freezes mainly in the pores (a)

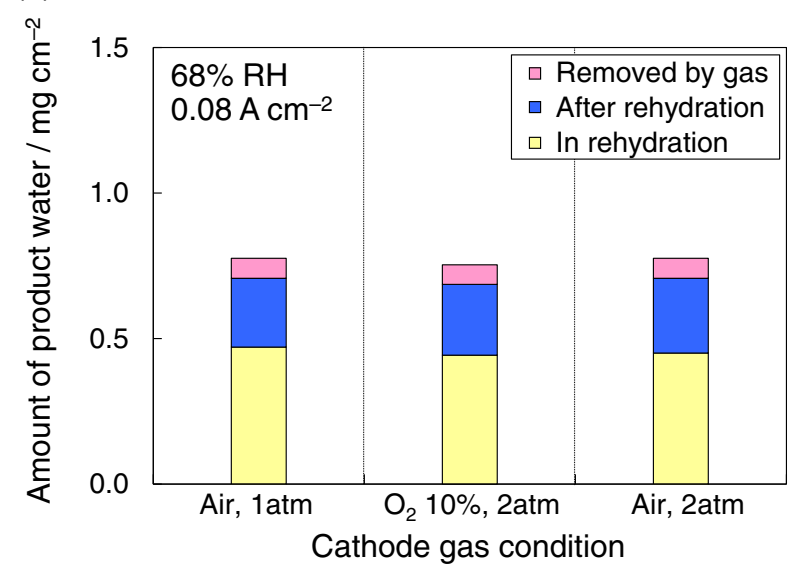

(b)

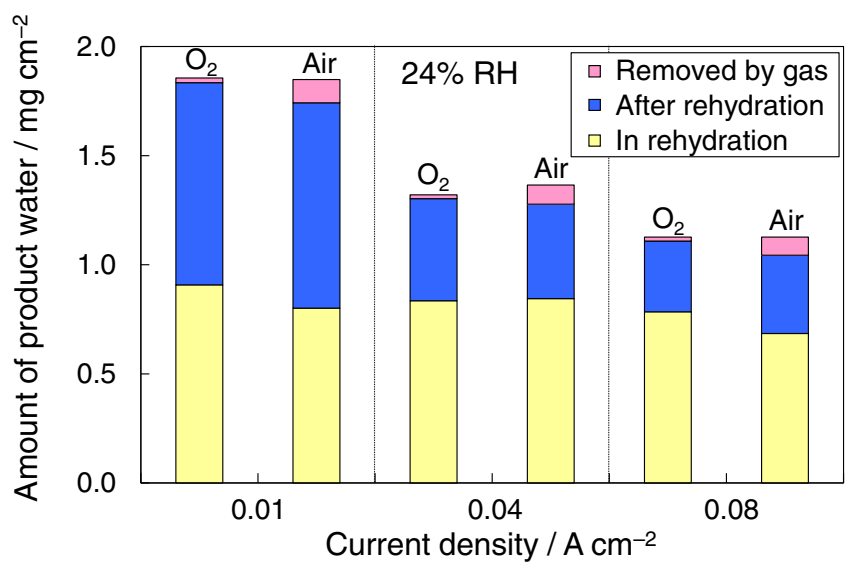

Figure 6. Amounts of water produced throughout the operation, divided into three: the estimated residual water produced in the membrane rehydration, after the end of the rehydration till the shutdown, and the estimated water removed by the reactant gases for different cathode gas conditions, (a) air at $1 \mathrm{~atm}, 10 \% \mathrm{O}_{2}$ at $2 \mathrm{~atm}$, and air at $2 \mathrm{~atm}$ (No. 7 to 9 in Table I), and (b) pure oxygen and air at $1 \mathrm{~atm}$ (No. 10 to 15 ). (a) $0.08 \mathrm{~A} \mathrm{~cm}^{-2}$, Air at 2atm

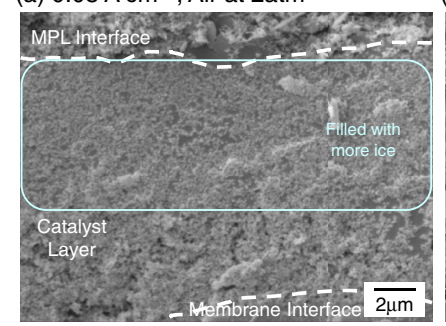

(b) $0.20 \mathrm{~A} \mathrm{~cm}^{-2}, \mathrm{O}_{2}, 68 \% \mathrm{RH}$ purge

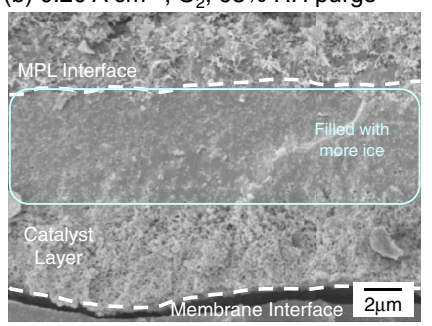

Figure 7. Cryo-SEM images of cross-sections of the cathode CL after the shutdown for different cathode gas conditions, (a) $0.08 \mathrm{~A} \mathrm{~cm}^{-2}$ with air at 2 atm (No. 16 in Table I) and (b) $0.20 \mathrm{~A} \mathrm{~cm}^{-2}$ with oxygen (No. 17).

of the cathode CL and that there is very little ice in the anode CL as in Fig. 4a. The results in Fig. 3 also showed that the amounts of residual water produced during the freezing are less affected by the wet purge conditions even when using 100\% RH nitrogen. This suggests that the effect of the water transport in the CL during the freezing is not large under the conditions of this study. Figures $8 \mathrm{a}$ and $8 \mathrm{~b}$ show images after the shutdown of the $0.20 \mathrm{~A} \mathrm{~cm}^{-2}$ operation with the $100 \% \mathrm{RH}$ wet purge condition at (a) $-20^{\circ} \mathrm{C}$ startup and at (b) $-30^{\circ} \mathrm{C}$ (experiments 18 and 19 in Table I). In Fig. 8a, the ice distribution across the cathode $\mathrm{CL}$ is similar to that with the $68 \% \mathrm{RH}$ wet purge (Fig. $7 \mathrm{~b}$ ), supporting 
(a) $-20^{\circ} \mathrm{C}, 0.20 \mathrm{~A} \mathrm{~cm}^{-2}, 100 \% \mathrm{RH}$ purge (b) $-30^{\circ} \mathrm{C}, 0.20 \mathrm{~A} \mathrm{~cm}^{-2}, 100 \% \mathrm{RH}$ purge
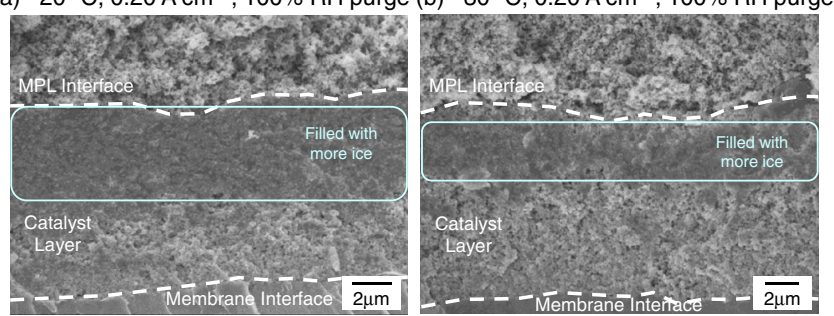

Figure 8. Cryo-SEM images of cross-sections of the cathode CL after the shutdown of the $0.20 \mathrm{~A} \mathrm{~cm}^{-2}$ startup with the $100 \% \mathrm{RH}$ wet purge condition at (a) $-20^{\circ} \mathrm{C}$ (No. 18 in Table I) and at (b) $-30^{\circ} \mathrm{C}$ (No. 19).

the above suggestion of a very limited effect of water transport on the ice distribution. At the lower temperature of $-30^{\circ} \mathrm{C}$ (Fig. 8b), the unevenness of the ice distribution is more pronounced than that after the $-20^{\circ} \mathrm{C}$ shutdown (Fig. 8a). This suggests that a locally higher temperature generated by the reaction does not dominate the active ice formation near the MPL and GDL sides here.

Finally, summing up and considering all the various observations we wish to hypothesize that the ability to supply electrons from the GDL side is an additional controlling factor in the active ice formation near the MPL late in the freezing period. Under usual conditions without ice formation, the electrical resistance and the changes in electron potential across the CL are negligible. However, under ice formation conditions, the electrical resistance in the CL may increase because of a deterioration in the contact resistance between the neighboring carbon agglomerates due to the ice formation. The increased electrical resistance deteriorates the electron supply to the reaction site, and induces the higher current density near the MPL side rather than the membrane side. At very low current densities like $0.01 \mathrm{~A} \mathrm{~cm}^{-2}$, the effect of the change in electron potential over the CL is small, resulting in only little effect of the large electrical resistance and there is a uniform reaction rate throughout the CL. Overall, suppression of the deterioration in thorough-plane electrical resistance achieves a uniform ice formation in the CL at higher current densities and increases the ice storage capacity in the CL to the level of that at lower current densities. The resistance measurements showed a slight increase in the cell resistance during the freezing period. However, the increase in the cell resistance during cold startup may be caused by various factors such as an increase in membrane resistance, and detailed measurements of the changes in the electrical resistance of the $\mathrm{CL}$ are necessary to validate the hypothesis suggested here. The ice formation behavior and the factors evaluated by the cryo-SEM analysis in this study present new additional details to assist in the understanding of the ice formation process, although the mechanism of the active ice formation on the MPL side is left as an issue to be further elucidated. Uniform ice formation in the cathode CL increases the water storage capacity and may also contribute to improve the durability of the MEA. Understanding of the ice formation mechanism will assist in identifying optimum structures of the MEA and operation parameters for cold startup under various conditions in the practical use of PEFC.

\section{Conclusions}

The cross-sectional ice distributions in the cathode CL of a $\mathrm{PEFC}$ during the process of $\mathrm{a}-20^{\circ} \mathrm{C}$ startup were investigated using cryo-SEM observations under a wide range of conditions. The observations showed that at a startup current density of $0.04 \mathrm{~A} \mathrm{~cm}^{-2}$, the pores of the CL are filled with ice from the membrane to the GDL sides during the freezing period; at higher current densities like $0.08 \mathrm{~A}$ $\mathrm{cm}^{-2}$ the progression of the ice formation becomes more pronounced at the GDL side and vacant pores remain near the membrane even after the shutdown of the cell; at a lower current density like $0.01 \mathrm{~A}$ $\mathrm{cm}^{-2}$, ice is growing nearly-uniformly and the pores in the CL are fully filled with ice. These different processes explain the experimental finding that the amount of ice accumulated in the CL, estimated from the cold start characteristics until the shutdown, decreases with increases in the startup current density.

To elucidate the reasons why the region with more active ice formation moves to the GDL side with vacant pores remaining near the membrane at the higher current densities, the effects of the supplied cathode gas were investigated. The experimental results showed that the estimated amount of ice in the CL and the observed ice distribution are less affected by the cathode gas conditions, even when using pure oxygen. This suggests the conclusion that the oxygen supply has a negligible effect on the active ice formation near the gas supply side even at the higher current densities. Similar changes in the ice distribution were also confirmed when the initial water content of an MEA was nearly-saturated and when the startup temperature was $-30^{\circ} \mathrm{C}$. These suggest that water transfer in the ionomer and generated heat due to the reaction are also not dominant in the uneven reaction rate across the CL thickness under the conditions investigated in this study. Finally, based on the experimental results we propose the hypothesis that the ability to supply electrons from the GDL side can be an additional controlling factor in the active ice formation near the MPL late in the freezing period.

\section{Acknowledgments}

This work was supported by JSPS KAKENHI grant Number 23686034. The authors thank K. Endo and Y. Tsukada (graduate students of Hokkaido University) for help in the cryo-SEM observation.

\section{References}

1. S. Ge and C.-Y. Wang, J. Electrochem. Soc., 154, B1399 (2007).

2. X. G. Yang, Y. Tabuchi, F. Kagami, and C.-Y. Wang, J. Electrochem. Soc., 155, B752 (2008).

3. Y. Tabe, M. Saito, K. Fukui, and T. Chikahisa, J. Power Sources, 208, 366 (2012).

4. Y. Hishinuma, T. Chikahisa, F. Kagami, and T. Ogawa, JSME Int. J., Ser. B, 47, 235 (2004).

5. L. Mao and C.-Y. Wang, J. Electrochem. Soc., 154, B139 (2007).

6. Y. Wang, J. Electrochem. Soc., 154, B1041 (2007).

7. R. J. Balliet and J. Newman, J. Electrochem. Soc., 158, B927 (2011)

8. Y. Tabe, H. Nakamiya, K. Kikuta, T. Chikahisa, F. Kagami, and K. Yoshizawa, Proceedings of the 13th International Heat Transfer Conference, 1/1 (CD-ROM) SOL-08 (2006).

9. S. Ge and C.-Y. Wang, Electrochem. Solid-State Lett., 9, A499 (2006).

10. R. Mukundan, Y. S. Kim, T. Rockward, J. R. Davey, B. S. Pivovar, D. S. Hussey, D. L. Jacobson, M. Arif, and R. L. Borup, ECS Trans., 11(1), 543 (2007).

11. I. Mayrhuber, F. Marone, M. Stampanoni, T. J. Schmidt, and F. N. Büchi, ChemElectroChem, 2, 1551 (2015).

12. K. Tajiri, Y. Tabuchi, and C.-Y. Wang, J. Electrochem. Soc., 154, B147 (2007)

13. E. L. Thompson, J. Jorne, W. Gu, and H. A. Gasteiger, J. Electrochem. Soc., 155, B625 (2008).

14. E. L. Thompson, J. Jorne, W. Gu, and H. A. Gasteiger, J. Electrochem. Soc., 155, B887 (2008).

15. J. Li, S. Lee, and J. Roberts, Electrochim. Acta, 53, 5391 (2008).

16. M. Saito, Y. Tabe, and T. Chikahisa, ECS Trans., 25 (1), 773 (2009).

17. K. Tajiri, C.-Y. Wang, and Y. Tabuchi, Electrochim. Acta, 53, 6337 (2008).

18. J. Biesdorf, P. Stahl, M. Siegwart, T. J. Schmidt, and P. Boillat, J. Electrochem. Soc., 162, F1231 (2015)

19. T. E. Springer, T. A. Zawodzinski, and S. Gottesfeld, J. Electrochem. Soc., 138, 2334 (1991).

20. Y. Tabe, R. Ichikawa, and T. Chikahisa, Energy Procedia, 28, 20 (2012).

21. T. J. Dursch, G. J. Trigub, R. Lujan, J. F. Liu, R. Mukundan, C. J. Radke, and A. Z. Weber, J. Electrochem. Soc., 161, F199 (2014). 